\title{
Foco e topicalização: delimitação e confronto de estruturas*
}

\author{
Carlos Alexandre Gonçalves** \\ Universidade Federal do Rio de Janeiro
}

\section{Abstract}

Left Deslocation (LD) and Focus (F) are phenomena characterized for putting in relief a constituent of the oral text. In other words, they are focusing strategies frequently used in Brazilian Portuguese (BP). For this reason, I intend to confront them in this paper, in order to check (a) their limits and (b) their structural domains. Thus, my purpose is to answer the following questions: (i) Are these phenomena independent, or do they exert mutual influence in at least some ways? (ii) Is there an obligated superposing between them? (iii) if not, what are the actuation domains (syntactic and/or phonological) of LD and F? (iv) What are the prosodic features of LD and F constituents? (v) What kinds of discursive-pragmatic phenomena motivate LD and F? My main aim is to show that LD shouldn't be analized as a focus marker in BP, because Focus must be faced as a prosodic category that require a Contrastive Intonation. 


\section{DEFININDO A FOCALIZAÇÃO}

$\mathrm{E}$ m estudos pautados na orientação teórica da Lingüística Textual (cf., p. ex., Koch et alii, 1991 e Grosz, 1981: 84-9), o termo 'Focalização' faz referência à direção de leitura que o falante/leitor tende a imprimir ao texto, podendo interpretá-lo através de diferentes perspectivas, de acordo com a ótica assumida.

Neste artigo, diferentemente, entendo por Focalização o ato de focalizar, ou seja, de acentuar, de ressaltar, de pôr em relevo/realcel evidência um determinado item do texto, seja (a) com o uso de estratégias propriamente textuais, como a topicalização e a clivagem de sentenças, seja (b) por meio de expedientes prosódicos, como a Entonação, seja (c) com atuação concomitante dos dois (cf. Gonçalves, 1997: 118-9).

Utilizando a metáfora da iluminação teatral, pode-se assumir que a Focalização funciona como uma espécie de refletor direcional que, no discurso/palco, vai se movendo em diferentes direções, colocando em Foco somente uma cena/constituinte de cada vez. Nesse jogo de representações, a totalidade do palco equivale ao texto e a parte iluminada corresponde ao que chamo de 'Focalização': porção do enunciado sobre a qual o falante/ator chama a atenção do ouvinte/platéia, clareando-a no texto.

O constituinte focalizado vem a ser, dessa maneira, a parcela do texto apresentada como a mais informativa/relevante para a audiência. Retomando a metáfora do palco, seria a cena em desenvolvimento, isto é, a colocada em primeiro plano. Diferentemente, os elementos fora de Foco (isto é, os não-alcançados pelo refletor) constituem informação apresentada previamente ao ouvinte (ou seja, equivalem às cenas já vistas e vivenciadas por atores e público) e, por isso mesmo, já conhecidas tanto pelo emissor quanto pelo receptor. 
A Focalização é, pois, fenômeno de natureza discursivopragmática, pois o usuário pode centrar sua atenção a uma parcela do enunciado que julgue relevante, enfatizando-a. Pode ser definida, assim, como o highlighting dado pelo falante à porção do enunciado na qual ele considera estar o núcleo da informação. Por essa razão, certas partes de um texto são enfatizadas não só porque são centrais (focais) no discurso, mas também porque são vistas através de certas perspectivas que afetam tanto o que o falante diz quanto o que o ouvinte interpreta. A noção de perspectiva é fundamental nos casos de 'Ênfase Contrastivo-corretiva', ${ }^{1}$ nos quais o falante faz uso da 'Focalização Prosódica' para corrigir ou para reiterar enunciados anteriormente expressos, não entendidos ou mal-interpretados por seu interlocutor.

Ainda levando em conta a noção de perspectiva, pode-se pressupor que os elementos fora de Foco são aqueles que o falante julga conhecidos por ele e por seu interlocutor. Mais restritivamente, são os ativados ou colocados em primeiro plano pelo co-texto ou pela situação precedente. Em outras palavras, constituintes fora de Foco fazem referência ao conhecimento comum ativado no momento do discurso (conhecimento de mundo e/ou partilhado). Dessa forma, o que está fora de Foco envolve informação old (ou dada). Diferentemente, o que é focalizado (ou enfatizado) é, necessariamente, new. New não porque não foi mencionado previamente, mas é new exatamente porque o falante tende a interpretar como não-suscetível de recuperação (a) nem a partir do texto precedente (co-texto); e (b) nem por meio do contexto pragmático (situacional) imediato. Parto, assim, do pressuposto de que a Focalização constitui, por sua própria natureza de "realçar elementos do enunciado", informação new.

As línguas do mundo dispõem de determinadas "pistas" (ou estratégias) para imprimir Focalização a um item do enunciado. Essas pistas funcionam como verdadeiros "gatilhos de Focalização" e são de duas naturezas distintas: (1) de um lado, envolvem mecanismos morfossintáticos, como o uso de sentenças clivadas e pseudo- 
clivadas; (2) de outro, recorrem a relações de proeminência acentual, exteriorizadas pelas variações nos elementos prosódicos físicos, como a duração e a freqüência fundamental. Nesse sentido, a Focalização, na qualidade de fenômeno discursivo-pragmático, manifesta-se tanto por meios textuais quanto por meios prosódicos (cf. Gonçalves, no prelo).

Com base nos "gatilhos" acima apontados, pude distinguir duas estratégias de Focalização utilizadas no português do Brasil. Reúno essas estratégias, detectadas na audição das entrevistas da Amostra Censo de Variação Lingüística (cf. Naro, 1986 e Scherre \& Oliveira e Silva, 1996), sob os seguintes rótulos genéricos: (a) Focalização Textual, a que faz uso de mecanismos lingüísticos presentes na linearidade do texto (recursos morfossintáticos, mais especificamente), como a (i) topicalização, (ii) a clivagem de sentenças, (iii) a marcação do grau e (iv) o emprego de advérbios focais, entre outros expedientes textuais; e (b) Focalização Prosódica, cujos meios de sinalização da Ênfase não se encontram expressos na linearidade discursiva, uma vez que envolvem recursos de natureza suprassegmental (saliência prosódica). ${ }^{2}$

Concluindo, a Focalização vem a ser fenômeno discursivopragmático, visto estar vinculada às estratégias argumentativas e ao conteúdo informacional do enunciado (isto é, à embalagem da informação). Essa categoria lingüística, cujos conteúdos semânticos predominantes são (a) contraste e (b) intensificação, pode vir manifesta, no português do Brasil, de duas formas, na maioria das vezes sobrepostas: (i) a sintática e (ii) a fonológica. Neste texto, analisarei, mais restritivamente, o relacionamento entre o 'Foco' (uma das três estratégias de 'Focalização Prosódica') e a 'Topicalização' (uma estratégia de 'Focalização Textual'), mostrando os pontos de convergência e de divergência entre eles no que diz respeito à variedade de estrutura lingüistica a que se aplicam. 


\section{RECORTE DA ANÁLISE E OBJETIVOS}

Como se pôde notar a partir Seção 1, o fenômeno da Focalização permite incrementar uma série de discussões a respeito (i) do mapeamento dos recursos existentes para destacar porções do texto nas línguas do mundo; (ii) do grau de conexão entre a Sintaxe e a Fonologia; (iii) da separação entre estratégias sintáticas e fonológicas usadas para fins de ênfase; e (iv) da dependência ou não do módulo prosódico para conferir highligthing a determinadas porções do enunciado.

Assinalei mais acima que a Topicalização é uma das estratégias sintáticas de que se serve o português do Brasil para pôr em evidência um elemento no texto conversacional. Esse mecanismo é denominado de 'Focalização Textual', nos termos de Gonçalves (1997), por ser lingüisticamente motivado, visto envolver alterações na seqüenciação canônica dos termos da sentença, que são deslocados para a posição inicial (i) para efeitos de contraste ou (ii) para introduzir novo tópico discursivo.

Encarado como estratégia prosódica de Focalização, o fenômeno do Foco Contrastivo funciona como uma espécie de "Gatilho de Inferência Conversacional", uma vez que proporciona estabelecimento de confronto entre elementos do enunciado, cabendo à audiência a tarefa de recuperar, no fluxo da interação, a relação de contraste que o falante pretendeu veicular. O termo 'Foco' fica, portanto, restrito ao rótulo dos segmentos da sentença que venham a receber algum tipo de proeminência fonológica (acentual e/ou rítmica), através de uma relação contrastiva com outro, previamente expresso ou inferido pelo contexto situacional.

Em decorrência de os dois fenômenos caracterizarem-se pela colocação de um termo em destaque no texto, isto é, serem estratégias de Focalização, pretendo confrontá-los neste texto, a fim de observar (a) os limites de cada um e (b) a variedade de estrutura lingüistica a que se aplicam. Nesse sentido, objetivo discutir questões como as que se seguem: (i) Topicalização e Foco atuam em solidariedade para realçar porções do enunciado? (ii) há sobreposição categórica entre eles? (iii) se não, qual é o domínio de exteriorização 
de um e de outro? (iv) quais são as características prosódicoentonacionais de constituintes topicalizados e focalizados? (v) que fenômenos discursivos estão por trás de sua materialização, isto é, o que pragmaticamente motiva o Foco e a Topicalização?

O principal propósito da exposição é o de mostrar que a Topicalização não deve ser vista como construção marcadora de Foco na língua portuguesa, aqui entendido como categoria de exteriorização prosódica que obriga Entonação Contrastiva. Dessa maneira, procuro validar a suposição de Callou et alii (1993: 356), para quem $a$ construção Top é pouco utilizada para marcar Foco, devendo os falantes cultos preferir, para isso, outras variantes, como, por exemplo, as construções clivadas, ${ }^{3}$ do tipo Foi SN que SV.

\section{TOPICALIZAÇÃO E FOCO: CONVERGÊNCIAS E DIVER- GÊNCIAS}

Analisando o fenômeno do SN inicial e externo à sentença, Callou, Moraes \& Leite (1993), Callou et alii (1993) e Torres Morais (1996) optam por distinguir entre Topicalização (doravante TOP) e Deslocamento à Esquerda (doravante DE), seguindo a orientação pioneira de Pontes (1983 e 1984). A diferença entre esses dois tipos de construção, de caráter derivacional, está na possibilidade de vinculação do SN externo a uma categoria vazia (TOP) ou a um elemento pronominal (DE) no interior da sentença que o segue (Callou et alii, op. cit.: 315).

Aparentemente não-complexa, a distinção não é de todo aceita pelos lingüistas que se dedicaram ao tema, como Pontes (1983: 12150), por exemplo, que mostra não constituir, no português do Brasil, tarefa simples distinguir as construções TOP das DE porque, como aponta à página 131, não há diferença muito nítida entre as Ss com pronome e as Ss sem pronome. Em outras palavras, a autora observa que a opcionalidade do pronome em nossa língua, decorrente da rica morfologia verbal, faz com que os dois tipos de construção se neutralizem. Com isso, discute se a distinção se sustenta do ponto- 
de-vista sintático e do ponto-de-vista discursivo. Valendo-se da observação e da análise de alguns exemplos, sugere que a dicotomia é válida somente para casos mais "polares" (ou extremados), havendo, em contrapartida, muito mais casos limítrofes, em que as duas construções de fato não se distinguem.

Pontes (op. cit.) observa que é em termos discursivos que a polarização entre TOP e DE se torna mais visível. Assim, afirma que o primeiro fenômeno é usado com maior freqüência para mudar de um tópico a outro, contrastado com o anterior, mas relacionado com ele. O segundo, diferentemente, permite que se dê continuidade à conversa, tendo, pois, função eminentemente coesiva na estruturação do discurso. A autora acredita que, para os casos mais evidentes, é possível estabelecer as seguintes tendências:

\begin{tabular}{|c|c|}
\hline Topicalização & Deslocamento à Esquerda \\
\hline sem pausa (ou com pausa breve) & com pausa (ou com pausa longa) \\
\hline sem pronome & com pronome \\
\hline função de continuidade tópica & função coesiva \\
\hline contrastivo & não-contrastivo \\
\hline com SNs tanto definidos, como não & com SNs definidos, dados \\
\hline
\end{tabular}

Quadro 1 - Principais traços distintivos entre Topicalização e Deslocamento à Esquerda, na visão de Pontes (1983: 146).

Exemplos desses dois tipos de construções podem ser vistos em (01) e (02) a seguir, respectivamente para TOP e para DE. Nesses dados, constituintes focalizados figuram em caixa alta se - e somente se - também estiverem em Foco do ponto de vista prosódico. O restante da sentença é grafado em outro tipo de letra, haja vista constituir o resíduo: ${ }^{4}$

(01) Eu trabalhei um ano e meio... um ano e meio como entregador... que eu

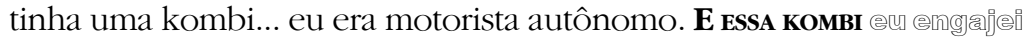

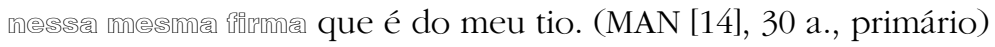


(02) Aí, nos fomos p(a)ra casa dela. Eu de carro e ele de ônibus. A GLória, eu

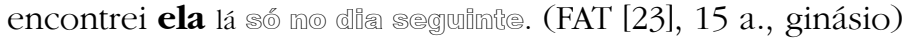

O trabalho de Callou et alii (1993: 355) evidenciou ser a distinção TOP/DE mais saliente do ponto de vista sintático-discursivo que do ponto de vista entonacional. Dito de outra maneira, os traços prosódicos não permitiram diferenciar nitidamente as construções topicalizadas das deslocadas à esquerda, porque, nas palavras dos autores,

"a diversidade de padrões encontrada para TOP, seja de curva entonacional, seja de pausa, também é encontrada para DE, o que mostra que a ambigüidade eventual da estrutura SN (...Ø...) não é desfeita pelo nível suprassegmental".

Quanto à atuação de fatos prosódicos nas duas construções tomadas em conjunto, Callou, Moraes \& Leite (1993: 94) mostram ser a Prosódia traço redundante a acompanhar a distinção sintática: ela só é traço distintivo nas construções tópico/comentário vs. sujeito/ predicado, sendo, por vezes, o único fator a distinguir as duas estruturas. Em outras palavras, no português do Brasil a dicotomia TOP/DE não se sustenta muito em termos entonacionais. Os resultados de Torres Morais (1996: 636-40) confirmam essa mesma tendência para o português da Europa. Aqui, há, portanto, uma espécie de "casamento monogâmico" entre Sintaxe e Prosódia, dando mostras de um relacionamento do tipo associacionista ${ }^{5}$ entre esses domínios da Gramática, uma vez que o segundo parece gerado a partir do primeiro, podendo ser concebido como traço redundante (ou reforço) em relação a ele.

No que diz respeito à relação Prosódia-Sintaxe na atribuição de Focalização aos constituintes topicalizados ou deslocados à esquerda, acredito não ser a informação sintática relevante para a veiculação do contraste (Foco), muito embora haja sobreposição na maioria dos dados a que tive acesso (cf. Gonçalves, 1997). De fato, os resultados advindos dos trabalhos de Callou, Moraes \& Leite (1993), Callou et alii (1993) e Torres Morais (1996) parecem acenar para o fato de não ser o Foco dependente de TOP ou de DE. 
TOP/DE e Foco são fenômenos distintos e definidos, inclusive, em diferentes domínios da Gramática. No primeiro caso, encontramse fatos discursivos manifestos exclusivamente pela Sintaxe (cf. Pontes, 1983 e 1984; e Torres Morais, 1996), ao passo que no segundo evidencia-se um fenômeno discursivo-pragmático manifesto, no português do Brasil, principalmente pela Fonologia. ${ }^{6}$ Além disso, TOP/DE não são construções marcadoras de Foco, aqui entendido como categoria de exteriorização prosódica que obriga Entonação Contrastiva. $^{7}$

A propósito da distinção TOP/DE vs. Foco, Callou et alii (op. cit.: 356) tecem o seguinte comentário, brevemente apresentado na Introdução deste artigo:

“(...) A inexistência de um padrão que só ocorra com Tópico/ Comentário leva-nos a crer que a construção de marcar foco através dessa posição é pouco utilizada, devendo os falantes cultos preferirem para isso outras variantes, como, por exemplo, as construções clivadas do tipo Foi SN que SV".

O Foco, revestindo a função de estratégia prosódica de Focalização, pode incidir em qualquer constituinte do enunciado (palavras, morfemas, sintagmas e pequenas orações), entre os quais também se incluem casos de TOP ou DE. Acredito que a freqüente superposição se justifica em termos de graus de "novidade" (informação nova) no discurso: Foco e TOP/DE incidem, necessariamente, em elementos novos e, por isso, tendem a aparecer conjugados na tarefa de veicular o contraste.

A sobreposição entre as Focalizações 'Textual' e 'Prosódica', em casos de TOP/DE, de forma bastante semelhante à ocorrida com as construções clivadas, caracteriza mais de oitenta por cento dos dados. De fato, em 83,1\% das sentenças TOP/DE analisadas (isto é, em 79 dos 95 dados), houve incidência de Foco Contrastivo. Novamente aqui, há uma espécie de "enlace" entre Sintaxe e Fonologia quanto ao ato de pôr em realce/relevo/destaque um item do texto. No entanto, constituintes topicalizados e sentenças clivadas, principais estratégias textuais de Focalização, podem não veicular 
informação contrastiva e, por isso, não estarem categoricamente sobrepostos com o Foco.

Em texto de 1981, Prince já observara que, em inglês, a existência de contraste não constitui efeito necessário à topicalização de constituintes. No que diz respeito ao PB, estou bastante convencido de que o contraste também não é essencial em sentenças com deslocamentos para a posição de SN inicial e externo, sejam eles casos típicos de TOP ou de DE. Os exemplos de (03) proporcionam confirmar essa hipótese. Observe-se, entretanto, que eles podem transformar-se em contrastivos, mediante a Entonação que lhes seja conferida. Isso constitui evidência de que o Acento Enfático ${ }^{8}$ é, no $\mathrm{PB}$, o verdadeiro elemento atribuidor da significação contrastiva, cabendo ao deslocamento para o início da sentença, isto é, à construção sintática, o caráter de redundante. Confira-se, então, a contraparte enfática de (03), logo a seguir, nos exemplos prototípicos de (04).

(03) a. Esse computador, eu comprei quando (es)tava trabalhando lá na Companhia. (PAU [20], 19 a., 2o. grau)

b. A Abigail, não se pode confiar nela não que ela já amostrou pra gente que é fofoqueira. (JAQ [63], 10 a., primário)

(04) a. Esse Computador, eu comprei quando (es)tava trabalhando lá na Companhia. (não comprei essa máquina de escrever elétrica, por exemplo)

b. A ABigaIL, não se pode confiar nela não porque ela já amostrou p(a)ra gente que é muito fofoqueira. (mas a Celeste ou a Madalena não, porque são sinceras)

A distinção entre TOP/DE e Foco pode se dar também por meio do tipo de informação transmitido pelo constituinte posto em evidência na conversa. Assim, elementos topicalizados necessitam representar entidades referenciais não necessariamente contrastantes (cf. Prince, 1981), ao passo que elementos-Foco requerem informação obrigatoriamente contrastiva pois, nos dizeres de Braga \& Oliveira e Silva (1984: 27), precisam representar atributos ou valores de 
atributos. Confiram-se os exemplos (05) e (06) a seguir. Eles parecem confirmar essa hipótese:

(05) (...) Fiquei p(a)ra segunda época só no Cláudio ... português, eu passei, mas raspando ... matemática eu tenho que ficar estudando... estudando

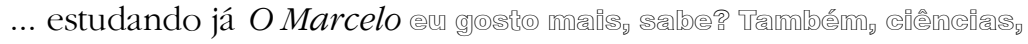
๓อ̊?? (ROS [52], 12 a., ginásio)

(06) (..) Ele ganhou um cachorro... um pastor alemão... não, um pastor não...

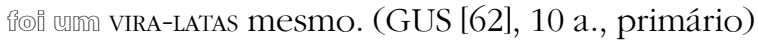

Casos de Topicalização que envolvam algum tipo de enumeração também são freqüentemente acompanhados de Foco (Acento Enfático). Isso acontece em (07) abaixo, em que os referentes enumerados contrastam mutuamente.

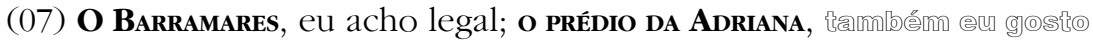
porque sempre tem festa; O PRÉDIO DO MEU TIO, eu acho chato porque é muito silêncio lá. (GUS [62], 10 a., ginásio)

A diferença entre Topicalização/Deslocamento à Esquerda, de um lado, e Foco, de outro, encontra evidências mais consistentes em termos prosódicos. Constituintes deslocados para a posição de SN inicial externo à sentença apresentam, no que diz respeito à última sílaba, duração notadamente superior à registrada para termos movidos focalizados. No entanto, quanto à duração da sílaba tônica, a situação se inverte. Constituintes unicamente topicalizados/ deslocados para a esquerda (isto é, não-focalizados prosodicamente), comparativamente aos constituintes-Foco ${ }^{9}$ apresentam duração sem dúvida alguma menor na tônica. O Diagrama (A) a seguir ilustra essa distribuição. 


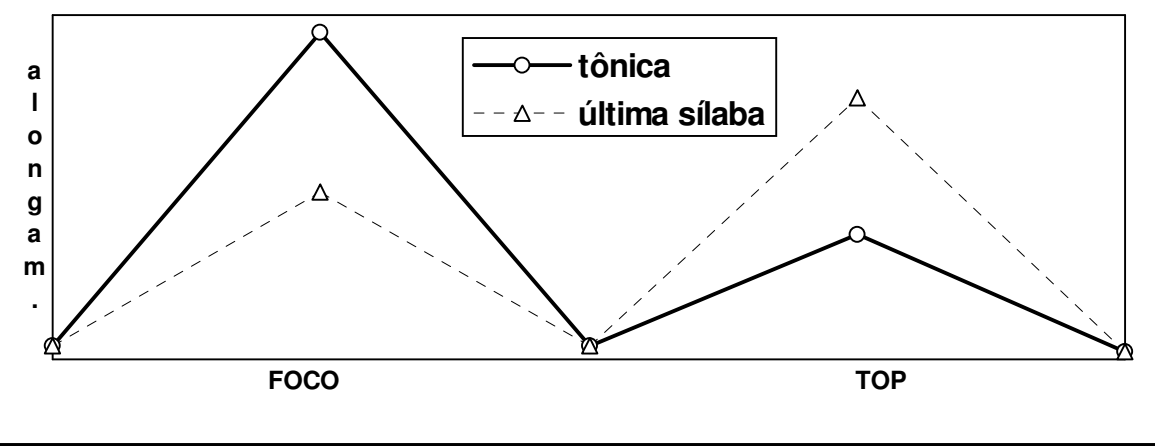

Figura A - Contraste de durações entre constituintes movidos topicalizados e constituintes movidos focalizados.

Ao que tudo indica, a diferença quanto à duração na última sílaba do termo posto à esquerda da sentença encobre distinção em termos de domínios prosódicos, tomando-se por base a proposta de categorização encontrada em Nespor \& Vogel (1986 e 1989). TOP/ DE conduzem necessariamente à presença de fronteira prosódica maior à direita do constituinte deslocado, ao passo que o Foco parece não afetar a construção dos constituintes fonológicos, não implicando, pois, estabelecimento de limites prosódicos mais rígidos.

A existência de maior ou de menor pausa proporciona corroborar a hipótese acima aventada, haja vista o Foco promover "silêncio" bem menor entre os constituintes (o SN inicial e o restante da sentença, como na Figura (B) abaixo). Em outras palavras, a pausa é maior em TOP/DE (chega a atingir 110 ms de duração) que em Foco (com apenas $35 \mathrm{~ms}$, em média), como se pode constatar pelo Diagrama (B) a seguir. 


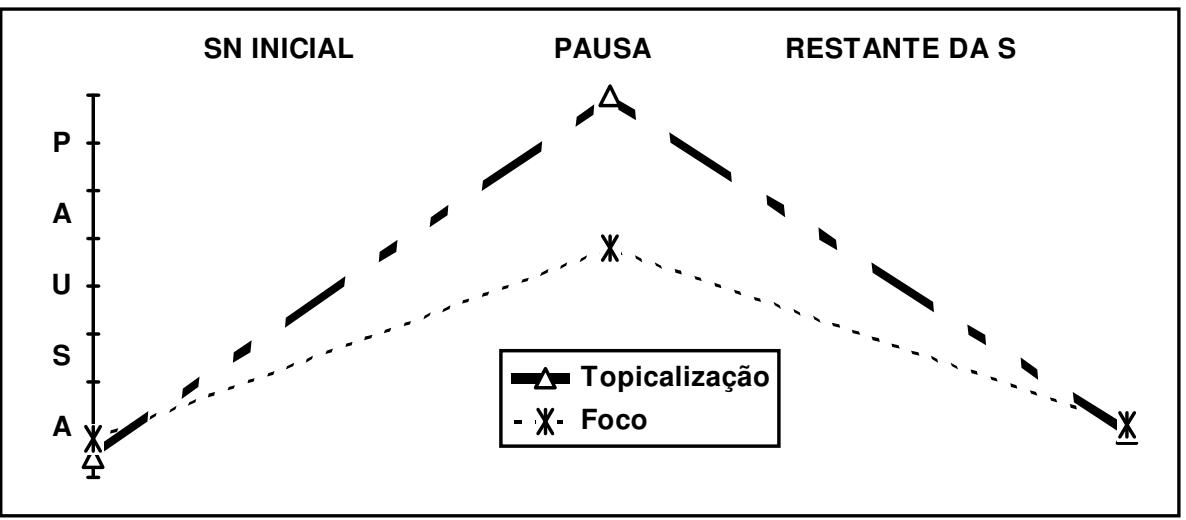

Figura B - Contraste de Pausa, na fronteira de constituintes à esquerda (Top e Foco).

Com base nessas duas distinções - (a) a duração na última sílaba e (b) o tempo de pausa entre os constituintes - pode-se pressupor que o Foco em posição inicial difere de TOP/DE por ter como domínio o Sintagma Fonológico ( $\varphi$ : 'Phonological Phrase'). TOP/DE, ao contrário, têm como domínio a Frase Entonacional (I: 'Intonational Phrase'). Esquematicamente, teríamos a seguinte correspondência: ${ }^{10}$

\begin{tabular}{|c|c|c|c|}
\hline A & $\begin{array}{c}\text { CAR ta } \\
\uparrow \unlhd\end{array}$ & $\begin{array}{c}\wedge \text { eu enviei pra ela } \\
]_{I}\end{array}$ & $\begin{array}{c}\text { 'A CAR ta eu enviei pra ela } \\
{\left[\begin{array}{l}\boldsymbol{y} \\
\boldsymbol{y}\end{array}\right] \boldsymbol{\varphi}}\end{array}$ \\
\hline \multicolumn{3}{|c|}{ TOPICALIZAÇÃO } & FOCO \\
\hline
\end{tabular}

Figura C - Domínio da Topicalização e domínio do Foco: análise contrastiva

Como representei em (C), o domínio em que opera o Foco é o 'Sintagma Fonológico' ('phonological phrase' ou $[\varphi]$ ), tomando por base a terminologia utilizada por Nespor \& Vogel (1986 e 1989). Essa categoria prosódica, nas palavras das autoras, vai além da unidade vocabular, em decorrência de constituir-se de duas ou mais peças lingüisticas (átonas ou tônicas), vinculadas a uma palavra fonoló- 
gica $(\boldsymbol{\omega})$ nuclear, num grupo intercorrente e emitido de uma só vez, sem qualquerpausa silenciosa. Dessa maneira, consiste numa porção da frase entonacional (I), articulada num conjunto fonético significativo, subordinado a um só acento predominante.

Com o intuito de validar a idéia de que o Sintagma Fonológico $[\varphi]$ funciona como domínio de aplicação do Foco - mas não de TOP/ DE - trago à tona os seguintes argumentos:

(1) Lehiste (1970: 83-5) evidencia que a pausa silenciosa vem a ser um dos principais indícios de agrupamentos prosódicos no interior do Grupo Entonacional. Partilhando dessa tese, Selkirk (1984: 121) mostra que quanto mais longas elas forem, maiores serão as fronteiras entonacionais. Assim, as categorias prosódicas tendem a se diferenciar pela duração das pausas. Em todos os dados de Foco testados laboratorialmente, ${ }^{11}$ constatei a presença de uma pausa - que varia entre $30 \mathrm{~ms}$ e $60 \mathrm{~ms}$ - antes e depois do termo/expressão que recebe o Acento Enfático, delimitando a porção do texto propriamente contrastada. Esse silêncio, no entanto, pode ser considerado breve, caso comparado ao existente depois de SNs TOP/DE, que chega a atingir $110 \mathrm{~ms}$ de duração (em média, 100\% a mais); ${ }^{12}$

(2) para corroborar a proposição apresentada no item (1), irei me escudar na afirmação de Viana (1987: 110), para quem é necessário postular diferentes domínios prosódicos (...) que encontrem justificação em processos fonológicos com limites em unidades entre a palavra e a frase ou o enunciado. Em função disso, buscarei subsídios no fenômeno de assimilação consonantal estudado por Scherre \& Macedo (1989), a fim de mostrar que o Foco de contraste não ultrapassa o limite de $[\varphi]$, por não bloquear a aplicação dessa regra.

Mattoso Camara Jr. (1972: 41) mostra que as sibilantes portuguesas se neutralizam na posição de travamento silábico, haja vista que ficam surdas diante de pausa ou de consoante surda (...) e sonoras diante de segmento sonoro. A especificação da fricativa em 
[+/- sonora] irá depender, portanto, do contexto fônico imediatamente seguinte. Scherre \& Macedo (op. cit.: 119) evidenciam que esse condicionamento independe de fatores sociais, sendo categórico nos dados da Amostra Censo de Variação Lingüística (cf. Naro, 1986 e Scherre \& Oliveira e Silva, 1996).

Nos exemplos abaixo, observa-se que a assimilação ora em exame só não se aplica nos últimos casos, nos quais o objeto direto foi alçado para a esquerda, através de TOP. Pode-se pressupor, portanto, que essa regra de sonorização opera no limite máximo de $[\varphi]$, sendo bloqueada por [I], em função da pausa que essa categoria prosódica exige. Como a existência de Foco não bloqueia o vozeamento, independentemente de sua posição em onset ou em núcleo de Grupo Entonacional, parece-me razoável concluir que o Acento de contraste não leva à fronteira de [I], limitando-se, pois, ao $[\varphi]$. Confiram-se os enunciados a seguir, nos quais a realização do arquifonema /S/ figura sob a transcrição ortográfica:

(08) [ OS DOCES ] $\boldsymbol{\varphi}$ estavam gostosos; não as frutas. [+ Foco] [3] [Z]

(09) [ AS CERVEJAS GELADAS ] $\boldsymbol{\varphi}$ Maria disse que trouxe. [+ Foco] [3] [Z]

(10) Ele trouxe pra nós [ AS CERVEJAS ] $\boldsymbol{\varphi}$ os salgados não. [+ Foco] [Z] [Z]

(11) [ As cervejas ] I // ele disse que ia trazer ontem de carro. [+ TOP] [S]

(12) [ Os doces ] I // a irmã dela ainda não fez. $[+\mathrm{TOP}]$

$\left[\int\right]$

Outro processo segmental que confirma fronteira de [I] após TOP/DE é o sândi vocálico externo, fenômeno estudado por Bisol (1992). Observe-se que no exemplo (13) o primeiro membro do contraste, sobre o qual recaiu o Acento Enfático, não impede a crase 
dos [a] contíguos, o que não acontece em (14) - caso em que o SN deslocado para a posição inicial não detém tal Acento -, no qual a regra é bloqueada. Confiram-se os dados:

(13) $\boldsymbol{A} \boldsymbol{D A L V A}$ aceitou que a filha ficasse com o namorado; o seu Sulapa [a] não. [+ Foco]

(14) Com o seu Sulapa, a dona Dalva não implica não. $[+\mathrm{TOP}]$ [a] [a]

\section{4. À GUISA DE CONCLUSÃO}

Pelo que se expôs no decorrer do texto, pode-se concluir que TOP/DE, de um lado, e Foco, de outro, são categorias diferentes. Embora compartilhem a função de colocar em evidência um elemento do enunciado, TOP/DE e Foco são expedientes focalizadores de natureza distinta. No primeiro caso, têm-se fenômenos discursivos materializados sobretudo pela Sintaxe, o que justifica considerá-los estratégias de 'Focalização Textual'. No segundo, ao contrário, observa-se um fenômeno definido em termos discursivopragmáticos que vem manifesto pela Entonação, sendo considerado, portanto, estratégia de 'Focalização Prosódica' (cf. Gonçalves, 1997).

Após analisar alguns exemplos, frisei que TOP/DE não são construções marcadoras de Foco na língua portuguesa, muito embora haja sobreposição na grande maioria das vezes. Na verdade, o significado contrastivo dos termos alçados para a posição de SN inicial e externo à sentença só é garantido quando o Foco do enunciado vem a ser o constituinte TOP/DE. Caso contrário, TOP/ DE não veiculam informação contrastiva.

Em termos prosódicos, pode-se pressupor que a existência de Foco em elementos TOP/DE leva a restruturações em termos de constituintes prosódicos. Como destaquei ao longo da exposição, o domínio de TOP/DE é a frase fonológica [I]. Quando o Foco incide no termo posto à esquerda, há uma espécie de "rearranjo" na categorização prosódica, fazendo com que [I] seja analisado como 
sintagma fonológico $[\varphi]$. A duração da pausa entre o constituinte deslocado e o restante da sentença e o bloqueio ou não a processos fonológicos segmentais constituem evidências da restruturação.

Pelo que se expôs, pode-se concluir que a Sintaxe não exerce qualquer influência na distinção entre os fenômenos. Nos dois casos, tem-se um sintagma nominal extraposto para a posição inicial: o status sintático do constituinte movido é o mesmo em TOP/DE e em Foco. A distinção se sustenta mais em termos (i) semânticodiscursivos (noção de contraste, perspectiva e status informacional) e prosódicos (domínios hierárquicos), o que justifica dizer que o componente prosódico é independente e autônomo em relação ao sintático, não havendo isomorfismo entre as categorias de um e de outro: um mesmo material sintático (sintagma nominal) pode equivaler a uma frase entonacional (TPO/DE) ou a um sintagma fonológico (FoCO).

\section{NOTAS}

* Versão revista e ampliada de comunicação do mesmo título, apresentada no VIII Congresso da Associação de Estudos da Linguagem (Assel-Rio), realizado em outubro de 1997 no Fórum de Ciência e Cultura (FCC) da UFRJ.

** Doutor em Lingüística pela UFRJ e Professor Adjunto de Língua Portuguesa do Departamento de Letras Vernáculas da mesma Instituição.

${ }^{1}$ Entendo por 'Ênfase Contrastivo-corretiva' os casos de Focalização que envolvam algum reparo na conversa (cf. Levinson, 1983), pois o falante literalmente "emenda" o que diz, autocorrigindo-se. Esse tipo de Ênfase ocorre, por exemplo, em "Quer dizer, Joana não foi à festa de carro; ela foi de metrô".

${ }^{2}$ Em Gonçalves (1997), foram descritas três estratégias de Focalização Prosódica: (a) o Foco, (b) a Ênfase e (c) a Escansão Silábica, exemplificados abaixo, respectivamente:

(a) Não, não. Você entendeu tudo errado. O LADISLAU encontrou com a Béia; não o Josias.

(b) CHEIROOOOSO o perfume do Boticário que eu comprei no Shopping.

(c) O filme de ontem foi simplesmente $\boldsymbol{F E}$-NO-ME-NAL. 
${ }^{3}$ As sentenças clivadas, estudadas por Braga em inúmeros trabalhos (cf., p. ex., 1991, 1994 e 1998), também são estratégias de Focalização no português do Brasil. Em Gonçalves (1997), tais construções foram rotuladas de "Focalização Textual" por serem lingüisticamente motivadas, requerendo, na grande maioria das vezes, a presença do auxiliar ser seguido ou precedido de um elemento $Q U$.

${ }^{4}$ No escopo da Focalização, podem-se reconhecer três constituintes básicos: (a) o item propriamente enfatizado, isto é, aquele em evidência no enunciado; (b) o marcador focal, ou seja, o elemento responsável pela Focalização (que, como frisei mais acima, pode ser sintático ou fonológico); e (c) o resíduo, domínio que abrange os elementos do enunciado que estão desfocados.

${ }^{5}$ Em outras línguas, como o Marubo (cf. Costa, 1992), há dependência direta entre a Sintaxe e a Fonologia quanto ao contraste de termos.

${ }^{6}$ Investigando a natureza da interface sintaxe-fonologia no PB, Gonçalves (no prelo) evidenciou que as propostas de conexão podem ser agrupadas em três grandes vertentes: (a) associacionista, que acredita numa relação de um-para-um entre constituintes sintáticos e prosódicos; (b) dissociacionista radical, que rejeita qualquer vínculo entre sintaxe e fonologia; e, por fim, (c) dissociacionista moderada, que propõe a existência de módulo prosódico autônomo, independente do sintático, mas muitas vezes relacionado a ele.

${ }^{7}$ Manifesta basicamente pela elevação da freqüência fundamental em todos os membros do domínio prosódico (sintagma fonológico) a que se aplica (cf. Gonçalves, 1997).

${ }^{8}$ A proeminência acentual requerida pelo fenômeno do Foco pode ser acolhida sob o rótulo genérico de 'Acento Enfático', considerado, aqui, como "gatilho de Focalização Prosódica”. Isso porque um termo focalizado no discurso apresenta-se modificado em sua configuração prosódica tida por básica: uma de suas sílabas sobressai significativamente sobre as demais, criando alternância rítmica mais intensa entre batimentos fortes e fracos. Como o Acento é definido atualmente em termos de relações de proeminência, parece-me adequado o emprego da expressão ora defendida.

${ }^{9}$ Os resultados foram oferecidos pelo Programa de Análise Acústica 'CECIL', através da análise do enunciado "A carta, eu enviei para ela", pronunciado, com e sem Ênfase por dois informantes (um homem e uma mulher). O Objetivo de A é tão-somente o de exibir o comportamento prosódico-entonacional dos fenômenos no que diz respeito à duração da tônica e da postônica. Trata-se, portanto, de uma Figura e não de um Gráfico.

${ }^{10} \mathrm{Na}$ Figura C, foi utilizado o sistema de notação INTSINT, da autoria de Hirst \& Di Cristo (no prelo). O símbolo $(\boldsymbol{\uparrow})$ representa picos de $\mathrm{F} \varnothing ;(\boldsymbol{y})$ representa movi-

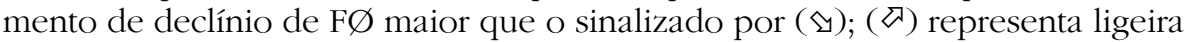
elevação. Acima das sílabas, os símbolos (-) e (=) representam duração longa e ultralonga, respectivamente. Maiores detalhes sobre o INTSINT são dados em Gonçalves (no prelo b). 
11 No total, foram testados laboratorialmente, via Programa CECIL, 35 dados de Foco Contrastivo: 25 de contrastes unilaterais, em que somente um membro do confronto recebe proeminência prosódica, e 10 de bilaterais, nos quais os dois termos igualmente recebem o Acento Enfático (cf. Gonçalves, 1997).

12 Outra característica prosódica que distingue TOP/DE e Foco vem a ser a sílaba que constitui o pico entonacional do constituinte-domínio. No primeiro caso, a tônica do grupo, além de ser mais longa que as demais, é mais alta do grupo ('car', de 'carta'). No segundo, é o artigo a sílaba mais proeminente do sintagma fonológico, visto apresentar intensidade e altura notadamente superiores às das demais sílabas do grupo prosódico em que figura.

\section{REFERÊNCIAS BIBLIOGRÁFICAS}

BISOL, L. . Sândi vocálico externo. In: ILARI, R. (org.). Gramática do Português falado. Campinas: Pontes/EDUNICAMP, p. 21-37, 1992.

BRAGA, M. L. \& OLIVEIRA e SILVA, G. M. Novas considerações a respeito de um velho tópico: a taxonomia novo/velho. Revista Letras E Letras. Uberlândia: Facs. Integradas de Uberlândia, 1: 27-40, 1984.

BRAGA, M. L. As sentenças clivadas no português falado no Rio de Janeiro. Organon. Porto Alegre: UFRGS/Instituto de Letras, 19 (1): 109-25, 1991.

. A dimensão dos constituintes no Português do Brasil. In: MOLLICA, M. C. \& MOITA LOPES, L. P. (orgs.). Linguagem, interação \& cognição. Rio de Janeiro: Tempo Brasileiro, 117: 17-26, 1994.

. \& LONGHIN, S. Estratégias de Focalização no Português de contato do Alto Xingu. Estudos da Linguagem: Atualidade \& Paradoxos. Rio de Janeiro: AsselRio/UFRJ/FAPERJ, 1: 300-8, 1998.

CALLOU, D. et alii. Topicalização e deslocamento à esquerda: sintaxe \& prosódia. In: Castilho, Ataliba (org.). Gramática do Português falado: as abordagens. Campinas: Ed. da UNICAMP/FAPESP, vol.3, p. 315-61, 1993.

CALLOU, D.; MORAES, J. A. de; \& LEITE, Y. de F. A topicalização no Português do Brasil: sintaxe \& prosódia. Anais do II Congresso da ASSEL-RIO. Rio de Janeiro: UFRJ/ASSEL-RIO, p. 89-97, 1993.

CAMARA JR. J. M. Estrutura da Lingua Portuguesa. Petrópolis: Vozes, 1972.

GONÇALVES, C. A. V. Focalização no Português do Brasil. Tese de Doutorado em Lingüística. Rio de Janeiro: UFRJ/Faculdade de Letras, 401p., mimeo, 1997.

GONÇALVES, C. A. V. (no prelo). O fenômeno da Focalização e a interface sintaxefonologia. DELTA. Campinas: EDUNICAMP. 
GONÇALVES, C. A. V. Sistemas notacionais da entonação e teorias fonológicas: cordialidade ou curto-circuito? Cadernos da Pós-Graduação em Letras. Niterói: UFF, (no prelo b).

GROSZ, B. Focusing and description in natural languages dialogues. In: JOSHI, W. \& SAG, L. (orgs.). Elements of discourse understanding. Cambridge: University Press, p. 84-105, 1981.

HIRST, D. \& DI CRISTO, D. (no prelo). A survey on intonation systems. Inédito.

KOCH, I. G. V. et alii. A organização tópica da conversação. In: ILARI, R. (org.). Gramática do Português Falado. Campinas: Pontes/EDUNICAMP, p.357-98, 1991.

LEHISTE, I. Suprasegmentals. Cambridge: The MIT Press, 1970.

LEVINSON, S. L. Pragmatics. Cambridge: Cambridge University Press, 1983.

NARO, A. J. Subsídios sociolingüísticos do Projeto Censo à educação. Rio de Janeiro: UFRJ/Faculdade de Letras, 412 p. mimeo, 1986.

NESPOR, M. \& VOGEL, I. Prosodic Phonology. Dordrecht: Foris Publications, 1986.

NESPOR, M. \& VOGEL, I. On clashes and lapses. Phonology, 6: 69-115, 1989.

PONTES, E. Topicalização e deslocamento à esquerda. Ensaios de Lingüística. Belo Horizonte: UFMG/FALE, 9 (1): 121-51, 1983.

. Sobre o conceito de sujeito em Português. Tese de Professor Titular. Belo Horizonte: UFMG/FALE, mimeo, 1984.

PRINCE, E. Toward a taxonomy of given/new information. In: COLE, P. (ed.). Radical Pragmatics. New York: Academic Press, 1981.

SCHERRE, M. M. P. \& MACEDO, A. T. Variação e mudança: o caso da pronúncia do /S/ pós-vocálico. In: NARO, A. J. (org.). Mecanismos funcionais do uso da lingua. Projeto final enviado à FINEP. Rio de Janeiro: UFRJ/Faculdade de Letras, 1989.

SCHERRE, M. M. P. \& OLIVEIRA e SILVA, G. M. Padrões sociolingüísticos. Rio de Janeiro: Tempo Brasileiro, 1996.

SELKIRK, E. Phonology and syntax: the relations between sound and structure. Cambridge: The MIT Press, 1984.

TARALLO, F. et alii. Rupturas na ordem de adjacência canônica. In: CASTILHO, A. (org.). Gramática do Português falado. Campinas: Pontes/EDUNICAMP, p. 2962, 1990.

TORRES MORAIS, M. A. Hipótese para o aparecimento das construções de topicalização na história do português. Estudos Lingüisticos XXV. Taubaté: UNAERP, (1): 636-41, 1996.

VIANA, M. C. Para a síntese da entoação do Português. Dissertação de Mestrado em Lingüística Portuguesa. Lisboa: Centro de Lingüística da UL/INIC, 1987. 